\title{
ECOLOGICAL COMMUNICATION CHALLENGES IN WASTE MANAGEMENT
}

\section{Dorottya Somfay*}

Corvinus University, Budapest, Hungary

dorottyasomfayl@gmail.com

Received:

September 2021

1st Revision:

November 2021

Accepted:

December 2021

* corresponding author

\begin{abstract}
Waste management has become a key issue in environment protection recently. The area is accompanied by various kinds of lobbying activities all around the world and it has the potential of directly affecting the everyday life of people and corporations. We analyse the factors that may influence social consciousness in the long run and what communication tools opinion leaders can use to reach out to the various social platforms. The objective of the research was to reveal hidden correlations in the field of waste management that influence societal awareness in Hungary and the relation between consumers and waste. We conducted the research by combining two methodologies, the REP-test (Role Construct Repertory) and the Storyline research methodology. Research has shown tension between the profession and the public sector, the main reason being the lack of communication and the different perception of the priorities of wasterelated matters. The phenomenon of interests vs stakeholders also became a recurring element, according to which only those topics in the waste management profession are embraced where there are underlying interests present or there is money behind them.
\end{abstract}

Keywords: social communication, sustainable development, environmental protection, ecological communication

JEL Classification: Q29

DOI: $10.54933 / \mathrm{jmbrp}-2021-13-2-6$

Somfay D (2021). Ecological communication challenges in waste management. Journal of Management and Business: Research and Practice, 13(2). doi: 10.54933/jmbrp-2021-13-2-6 


\section{Introduction}

Waste management in Hungary sees a number of transformations year after year, significantly influencing the prioritisation of the various fields of specialty, and in turn, the way these are communicated. The possible outcomes resulting from the various legal and proprietorship changes are as yet unpredictable, but the elite of the trade nevertheless bears the onus of what extent they are able to influence the present government's decision-makers in positively shaping our society's relation to waste. The waste pyramid defining and directing the waste management of European countries includes the hierarchy of fields that handle, dispose of, and (re)use wastes. The assessment and level of acceptance of these areas show tremendous variances both among the general population and in professional circles, also demonstrated by the not representative, nevertheless special qualitative niche survey we have conducted. Within environment protection, waste management has grown into a key area in its own right, with a multitude of lobbying activities connected to it worldwide, and with the ability to directly influence the everyday life of people and businesses. From the aspect of the future of waste management, it is necessary to examine when and how, what, through what, and to whom should be communicated. It is necessary to map the attitudes of the various classes of society, to enable efficient communication with them. The question is what means are utilised to achieve this, i.e. what are the driving forces and groups of society in Hungary, and are there any differences at all, or is this region driven by the same set of principles and organisational powers as our European neighbours? What communication means does this field have, how is a residential perception shaped, and how should this be supplemented? Do Hungary and the Eastern European region have any chance of catching up in this area - are we lagging behind in the first place - and if so to what demonstrable extent in comparison to the developed Western European states? I believe it is important to obtain a comprehensive picture of the current societal paradigm shaping process, and in that the communication background, from where a number of conclusions can be derived regarding future tendencies. Below I have drafted the stakeholder map of the area, i.e. the specific forces having a significant influence on this profession. Advancing on this basis, I have examined leading officers of the profession, and I have explored the topic using their system of terms and definitions. The research covers ecological communication and the opinion of several professional decision-makers of Hungarian waste management, by unifying two special research methodologies.

\section{Literature review}

This year will also bring several changes regarding waste management in Hungary that will profoundly influence the prioritisation and accordingly the communication of different fields. It is impossible to foresee all consequences of these transitions in the legal and ownership status; furthermore, it is also up to the professional elite in the field, to what extent they can influence the policy-makers within the current government so that the attitude of our society regarding waste should change in a positive way in the future. In European countries, waste management is determined and guided by the waste hierarchy that contains the hierarchy of fields that manage, dispose of, recycle and recover waste. (National Waste Management Plan, 2014-2020.)

Appreciation and acceptance of these fields are greatly varied among the population and the professional circles as well. This is well reflected in a non-representative, nevertheless gap-filling qualitative survey that we carried out earlier this year. Considering the future of waste management, we have to investigate what, when, how, in what media, and to what audience is worth communicating. (Kovács et al, 2019) We also need to map the attitudes of different social layers in order to reach out to them with efficient communication. The question is, what tools are available to reach our goals, which social groups, tendencies are the driving forces in Hungary? Is there a difference between us and Hungary's neighbours in Europe, or are we motivated by the same drives and organizing forces? What channels of communications are open and available for the education and mind framing of the population, and how can we broaden these channels? Do we and does the East-European region have a chance to catch up, are we lagging behind at all compared to the developed West-European states? 


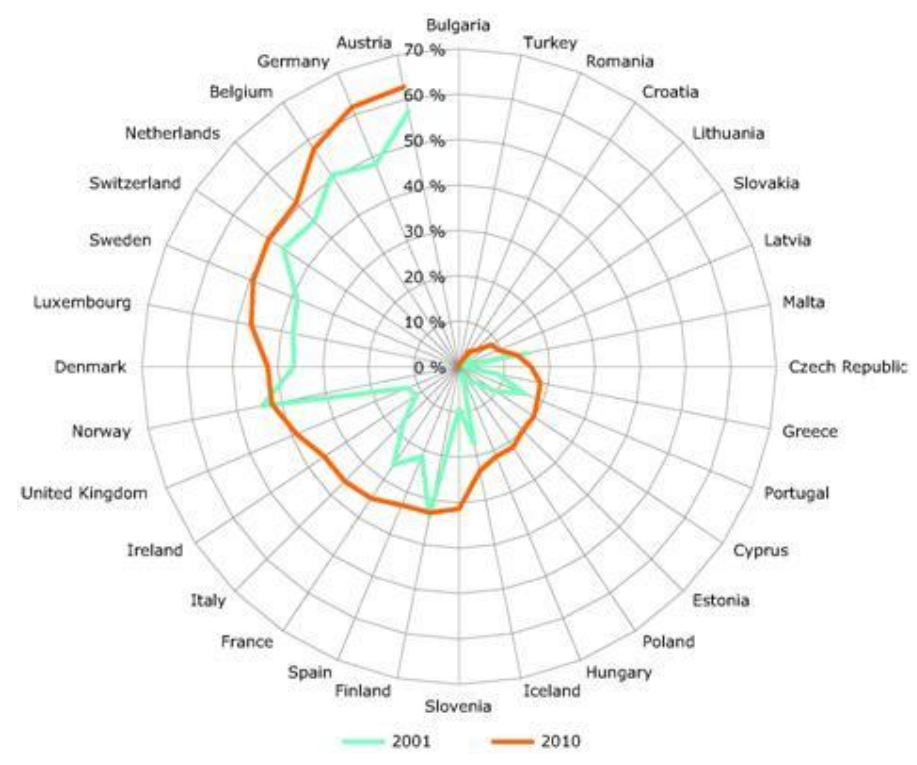

Figure 1. Municipal waste recycling rates in 32 European countries (eea.europa.eu, 2013.)

If yes, to what clearly recognisable degree and in what area? We hope to answer all these and most probably some further questions during our research. We think it is important to shape an overall image of the current public awareness programmes and especially their communication background that allows us to draw conclusions in reference to future trends. We also found it important to select a survey method that can achieve results beyond those produced by in-depth interviews based on pre-prepared questionnaires. Last year we ventured to map the stakeholder relations of the field in relation to what driving forces have considerable impact in this profession. Based on the results and moving on, this year we have examined the leaders of the profession and civil servants in relevant executive positions, focusing the subject based on their own set of concepts. (Kovács et al, 2019) Our survey refers to ecological communication, in particular certain opinions of several managers and decision-makers of Hungarian waste management, utilizing a combination of two specific research methods. The survey aims at exploring hidden relationships within the field of waste management that can influence social consciousness in Hungary and the consumers' relationship to waste. We also found it important to select a survey method that can achieve results beyond those produced by in-depth interviews based on pre-prepared questionnaires. Observing the specific field through the personal set of concepts of the subject plays a key role in this issue. Random comparison of individual concepts encourages a new way of thinking that has the potential of emerging new aspects, relationships, hidden dimensions. Thus we could reveal what can be communicated to the public, what the priorities are according to the management, what can be told and what not, and what kind of misconceptions dwell among the population. Due to our research, we can assert that we have an extensive overview of the professional aspects of our thesis, and step by step we can get fully involved with the establishment of our theory. (European environment agency, 2015) These three countries are relatively small and underdeveloped in terms of their geographical size and population, geopolitical importance, market size and aggregate demand, production, investment, export, and technological potential. According to many non-economic indicators (political stability, democratization, liberalization and institutionalization of society, law, infrastructure development, safety, security, investment, compliance with environmental and social standards, efficiency of the legal system, human rights respect, etc.), as well as economic indicators (purchasing power, rate of economic growth, foreign trade balance, current account deficit, public debt, inflation rate, unemployment rate, public expenditure, investments, etc.), they are characterized by a long-term transitional crisis of structural type. (Kovács et al, 2019)

\section{Methodological approach}

The objective of the research was to reveal hidden correlations in the field of waste management that influence societal awareness in Hungary and the relation between consumers and waste. It is important to select a research methodology that may exceed the results achieved by depth interviews 
by exploring such depths in the subjects that the party conducting the research/asking the questions is unable to explore by asking questions compiled beforehand. The key to this is to examine the field in question using the subject's own system of concepts. The random comparison of the particular concepts prompts the subjects to adopt a way of thinking that brings new aspects, correlations, and hidden dimensions to the surface. This allows exploring what can be communicated from the perspective of mind framing how the profession perceives the priorities and what misconceptions the population holds. We conducted the research by combining two methodologies, the REP-test (Role Construct Repertory) and the Storyline research methodology. Using these, we described fifteen concepts with the research subjects, identified by the subjects, then they explored the constructs and contrasts of these, and analysed them, supplementing them by telling a case study or story. Finally, we consolidated the results obtained and contextually compared them. Therefore, the topic of the interview was given by the research subjects, ad there was no questionnaire prepared in advance apart from the REP table. This is the essence of qualitative market research: it is not the researcher who determines the key features (constructs) of the particular topics; they are determined instead by the research subjects, the features of the topic in question being "extracted" from the subject.

\section{The hypothesis of the research}

RH 1.

On the one hand, our hypothesis is built on communication concerns, and in waste management, we see the root cause of the problem in the disproportionate popularisation attempts of waste processing activities. On the other hand, from the social science perspective, whether the coordination of this perception management process is managed appropriately through the societal systems concerned.

Here, we see points calling for development along the politics-education axis, and in accordance with my hypothesis, the topic is being deliberately postponed at the highest decisionmaking levels, not receiving the emphasis it should. As we specifically selected the decision-makers as the subjects of our research, I had confidence I would be able to map this situation.

RH 2.

In Hungary, the most popular activity promoting environmental awareness in the field of waste management is the selective waste collection, which is not expediential in connection with perception management.

Our greatest concern and problem prior to our research was the following, which also provided the fundamental hypothesis for my dissertation:

By popularising selective waste collection:

- Will consumers become environment-conscious?

- Will they understand the waste management system through this?

- $\quad$ Do they understand the path waste covers?

- $\quad$ Are they aware of the consequences of their waste-related habits?

- Why is only the importance of one particular waste stream is emphasized? Hungarian households consume an average of 125 beverage cartons each year. Only $21 \%$ of this, i.e. about 26 beverage cartons are collected selectively and recycled. This proportion is about $35-40$ in the member states of the European Union, but in certain member states, it can even reach 65 pieces.

Therefore, we examined the focus of communication with the present research, because I believe this is not right and in my opinion, the holistic opportunities the topic hold are not being utilised to their fullest potential in popularising communication activities, it is, therefore, no coincidence that the attitude change of the population has not shown any substantial change for decades.

RH 3.

According to our hypothesis, the professional elite is most suitable for exploring the hidden correlations; representative research covering the general population would only touch this topic superficially and the system of notions currently shaping the general situation could not be mapped fully.

Several studies surveyed over the recent years the environmental awareness of students of tertiary educational institutions and pupils of secondary schools and elementary schools, and their attitudes with respect to a particular environmental topic. Several groups of researchers survey at present the environmental attitudes of the pupils attending the forest school, with the help of questionnaires, concept maps, and other methods. One such research group (under the direction of 
Viktória KÖVECSES GŐSI, Bálint LAMPERT, Mrs. Tibor PETZ, and Mrs. Lajos CSENGER) examined how young people leaving the public education system thin of environmental questions and what behaviour they exercise in their connections with the environment. Data were recorded at nine faculties of Széchenyi István University in September 2019. The objective of the research was to assess the environmental attitude of the first-year students enrolling in the university, concerning sustainability and their knowledge of environmental issues, and to map their behavioural habits and emotions regarding the subject. Therefore, due to the availability of these researches, we did not start any representative research work, as these are available in our field.

RH 4.

According to our hypothesis, thermal utilisation should be a key element in waste perception management in Hungary but does not yet receive the political support it should.

RH 5.

The surrounding western states are further down this path according to our hypothesis, and we intended to prove - or contradict - this through research and processing of literature.

\section{Application of the REP and Storyline research methodologies}

\section{REP parameters}

George Kelly was the first personality theorist who regarded the cognitive and informational aspects of human existence as the dominant features of personality. According to his theoretical system titled The Psychology of Personal Constructs, a human is essentially a scientist, who, to achieve efficiency in life, strives to understand, interpret, anticipate, and control his personal world. The hallmark of Kelly's theory is the statement that likens the nature of human behaviour to that of a scientist. Kelly's Repertory Grid Technique is a qualitative market research method that can be broadly applied, although it is not in wide use in Hungary. The focal question of Kelly's cognitive theory is: how individuals perceive and interpret people and things in their surroundings. Kelly's approach called "personal construct theory" focuses on processes that enable a person to arrange and understand the events of his life. His theory is a modern cognitive approach, targeting the examination of the personality. In this respect, the emphasis is on how individuals perceive and interpret people and things in their surroundings. The construct theory focuses on the processes that enable people to understand their psychological living space. From this cognitive perspective, Kelly recommends a personality model based on the analogy that a human is like a scientist. It assumes that a human individual, just as a scientist studying him, establishes work hypotheses on reality, based on which it attempts to anticipate and control the events of his life. According to Kelly, therefore, life is characterised by people continuously fighting to understand the tangible world of their experiences. Man perceives his world through certain translucent, self-constructed patterns and schemes, and attempts to reconcile these schemes with the reality the world is made up of. These two do not always match perfectly. Without such patterns, however, the world seems to be an undifferentiated, homogeneous unity, which man is unable to comprehend. These "translucent patterns and schemes" were referred to by Kelly as constructs. In other words: a construct is a category of thinking, with the help of which the individual shapes and interprets the world of his/her experiences. This is a consistent way for man to make certain aspects of reality sensible. According to Kelly, man forecasts and constructs his personal experiences by creating their replicas. The significance of this process lies in that it provides a tangible basis for the individual to build expectations on the probably emerging events and to interpret their meanings. In the early stages of construction, the individual observes the general flow of processes and interprets them. Then he recognises a pattern of the events and their repetition in a field of experience. Finally, he devises a structure or meaning for the events experienced. This temporal flow of experience, interpretation and construction is known as the process of construction, i.e. the capacity of the individual to generalise his experiences in a meaningful form. The constructs are therefore significant from the perspective of forecast and control, as they enable the individual to anticipate the upcoming events through expectations. Without constructs, the life of the individual would be chaotic; he would not be able to sense the world consistently. If he were incapable of devising expectations for the future, the ongoing events would become intangible. The personal constructs enable the individual to create some sort of an order, rendering his world foreseeable. The constructs are not only bipolar, but they are also dichotomous. Kelly imagined that constructs are used as a yes-no nature, and not along the stages of a continuity. While he recognised that people know several dimensional stages, he handled this in a unique way. He presumed that the stages are the 
products of the organisation of dichotomous constructs. Organisation allows increasingly delicate distinctions as soon as the higher-level dichotomous decisions are followed by new decisions at lower levels. More specifically, when the events are experienced, the person observes that certain events seem to be similar to one another, have common features, and are different from other events. This cognitive process of observing similarities and differences leads to the creation of personal constructs. This means that only three elements (events or things) are required for the formation of a construct: two elements of a construct must be detected as similar and a third one as different from the former two. The mode as two elements are created as similar is called a construct or the similarity pole of the construct dimension and as the third element opposes the former two is known as the contrast pole of the construct dimension. It follows from this that every construct has a similarity pole and a contrast pole. Construct theory motivates one to discover how people interpret and anticipate their experiences in terms of similarities and contrasts. Based on this theory, Kelly developed the REP test to identify the important constructs that an individual uses to construct persons playing significant roles in the said individual's life. Summarizing the above, REP originally is a projective psychological test that targeted the exploration of important categories in the individual construction of social situations. Originally, a so-called list format was developed, later to be further developed into the grid format. To analyse the Grid - although Kelly did set up a mathematical scheme - software support is required, therefore the method could only gain popularity with the development of information technology and applied software. With the help of the method, the personal constructs of particular consumers can be explored and their detection and mental maps can be drawn. Its advantage is the quantification of the qualitative results, inherently ensuring the integration of qualitative-quantitative market research. Since the Repertory Grid Technique rather seeks to answer "How?" instead of "How many?", it helps to establish how a consumer thinks and detects, and what subconscious motivations guide his choices. A key advantage of the method over the interviews is that it completely eliminates the researcher's influence. In other cases, the researcher would always set out from his/her own system of constructs, inevitably influencing the outcome of the interview. The research is made up of two parts, first, the consumer is requested to select important/relevant notions from the research topic in question. Following this, the elements are examined, three at a time, compare the triads by identifying the feature in which two of the three elements are similar, while the third is the opposite of the other two. This created a dimension, determined by the consumer, on one of whose poles similarities is positioned (similarity of two elements against a third one), and the other pole contains the difference of the third element. For traceability's sake, the two similar elements are marked (X), and the third, bearing the feature of difference, is left unmarked. (O) In the test, a notion is compared with others on three occasions in a random manner, based on the points positioned as the array of a matrix. In addition, the test may also play a useful sole in selecting the communication or convincing strategies, as a consequence of which, the parties are aware of the other person's constructs, or can at least deduce them. The exploration of the constructs allows studying the dimensions the consumer uses in judging the topic in question. This exploration is however far from sufficient to describe how the system of mental constructs of the consumer functions. Two persons may identify the same construct, and yet we may use it quite differently, and thus, beyond verbal statements, we also find out that they may associate it with different meanings. To explore the use of constructs, the so-called "full grid" must be performed. For this, it is advisable not to regard the similarity and contrast poles of the construct as simple pairs of words, but a five-point scale.

The summary parameters and impressions of our REP research based on the above are:

1. $\quad 15 \times 15$ mesh, randomly positioned mesh in a matrix arrangement.

2. Points indicate in the row in question what is being compared to what.

3. $\quad 1$ concept is compared $3 \mathrm{x}$ with the others.

4. The system of test aspects are the constructs and the contrast.

5. The subjects are not influenced in nominating the 15 notions; they define their own scope of concepts within waste management. we considered this important because examining the topic through the communication expert's eye, topics and correlations may be overlooked that might have helped the topic advance.

6. The duration of running the survey on 1 subject lasts $60-90$ minutes.

7. The start of the survey is a monotonous and slow process, as the majority of subjects clarify the concepts and their background processes and situations upon comparing the first 3-4 of them. About halfway through the process, things accelerate, and all concepts and correlations overlap to about $90 \%$, and the stories begin to be more interesting at this point. This is because of going deeper, the subjects loses awareness of being recorded, and the system of concepts expounded beforehand lets the subject's inner world unfold with respect to the topic. (KELLY 1969) 
Storyline parameters

Storyline is not identical to storytelling, although they are built on one another, and are related methods. Storytelling supports communication though the power of the stories, while the storyline is the framework itself, the path leading to storytelling. Storytelling is as old as the history of mankind. Listening to stories stimulates the functioning of the right cerebral hemisphere, which is responsible for creativity, sensing and even for one's sense of humour. We can understand other people's emotions through stories. We connect to one another through stories: we tell what happened to us, we gossip, we tell stories and quote anecdotes. Our brain senses imaginary experiences and emotions in the same way as real events: be it a good book, theatre piece, film or a moving conversation with friends; if the story is good, we identify with the personae. Of late, new procedures appeared in the field of futurology that are on the one hand based on creativity, and on group thinking on the other. The storytelling method grew popular because the problems of the present and the future cannot be solved within the confines of the conventional system of values. Bringing new values to the surface may be greatly aided by the so-called storytellers, who, through their own subjective perception, may draft new events of the future. The mindset of storytellers is heavily oriented towards global awareness and openness, while their stories and visions of the future also express the versatility and diversity of the world. The storyline method was first developed at Jordanhill College in Scotland in the mid-6o, which is today part of Strathclyde University. The objective of the creators of the method (Steve Bell, Sallie Harkness and Fred Rendeli) was to develop an integrated approach of curricula that may be subdivided into parts A characteristic of the method is that it focuses on a story. This story or tale is wound around key questions. Key questions raise a problem each, which the students must solve, which carries the story forward. That's how students become part of the story. So, in order to progress, the active contribution is required, making even the unmotivated students motivated. A great advantage of this method is that it is not only linked to a particular subject but more than one subject may be concentrated into one topic. Child-orientedness was put in the focus, and their primary objective was to create appropriate classroom conditions for the students, promoting the acquisition of skills that are indispensable for learning. In the course of applying the method, students acquaint themselves with strategies that are equally applicable to the class, group, or individual works. The parts and episodes in the method are built on one another, ensuring progress and flexibility, and as the story progresses, the part of curricula to learn also unfolds. The participating students are urged to find the answers themselves, so they are made to face problematic situations, which they must solve with the help of their own knowledge and various sources of information. (MIKO 2017) In Hungary, it was the Institute of Educational Research and Development (Oktatáskutató és Fejlesztő Intézet, OFI) that compiled a guide in the Hungarian language, introducing the application of the storyline method to pedagogists. The Storyline method became accredited training in Hungary in 2015. (KÖVECSESNÉ 2015) In the research we conducted, achieving a similar openness in the subjects, we explored the present and future dimensions of waste management through the REP system of concepts. Therefore, this research method is capable of exploring deeper correlation in combination with the REP test than a depth interview would alone, as the subject uses his/her system of concepts to dig deep into the topic, analysing, evaluating, or expounding them. And in the research part of the Storyline method, the person conducting the research can urge the respondent to seek deeper connections. The integration of these two methods made it possible to obtain a comprehensive picture of the current waste management scenario's evolution in Hungary.

\section{Subjects of the survey}

We selected fifteen professional leaders, currently holding high and relevant positions in the state and local government sector, and also from the non-profit and the civic sector. Supplementing it with a testing nature - to ensure whether they exercise influence over the result of the research - we had the test filled by two additional persons. A consumer who identifies him/herself as wasteconscious, is well-read in the topic, and myself, too. Eventually, as the answers given by us would not have altered the result of the research in any way, we left my concepts in the core material of the research. 


\section{Conducting research and results}

The research has revealed what can be communicated in terms of societal mind framing, what the elite of the profession thinks, what the public can be told, and what misconceptions are present. How far can consciousness go in the present situation? Research has shown tension between the profession and the public sector, the main reason being the lack of communication and the different perception of the priorities of waste-related matters. Based on the reports by the professionals, it became evident that the problems of combustion and composting stand out by far. That every subject revealed a similar system of concepts and problem curve during the conversations, confirmed the appropriate selection of the subjects. The phenomenon of interests vs stakeholders also became a recurring element, according to which only those topics in the waste management profession are embraced where there are underlying interests present or there is money behind them: this is why there is no mobile composting, for instance, because there is no company that would manage it.

The REP test created 255 concepts related or associated with waste, based on which 31.5 hours of audio material and 65 pages of storyline supplementation were also created. From these, we filtered out three concepts referenced with outstandingly higher frequency: selective waste collection, utilisability of the material of the waste, utilisability for energy purposes, i.e. waste incineration, as it is more commonly known. As the first three had been mentioned more frequently than the others - and compiling their roles with the Storyline material - I think our research materials pointed out the most important or most problematic topics with the help of this method of highlighting.

The most outstanding result of the research is that based on the answers given by the research subjects, the Hungarian waste pyramid is different in comparison to those of our Western European neighbours and those of the Hungarian Waste Framework Directive as well. Recycling, i.e. selective waste collection is of a higher priority than the utilisation of the waste material. Although utilisation for energy purposes was only the third most frequently mentioned REP concept, it can be clearly demonstrated from the Storyline part that professionals opine the current decision-makers should place far greater emphasis on waste incineration. Further investments in this direction and the development of the already existing facilities/systems may be the way for Hungary to emerge and establish sustainable environment-conscious development.

The thought that health-consciousness is related to waste - these being built on one another and closely correlated in fact - was born as a comprehensive result of the research. It is not possible for an individual to be waste-conscious without checking the quality of the goods purchased, the effect it may have on human health, or what the product has been packaged into. It is interesting to examine the environment-conscious developmental curve that evolves in a consumer. First, messages find and convince the consumer on consciousness related to energy consumption, as individual involvement and interest is generated by demonstrably saving money through dedicated attention to the matter. Furthermore, if the principles of these (not only financial return) are incorporated in the individual's everyday life, but the individual may also become susceptible to activities such as selective waste collection or individually tailored healthy lifestyle programmes. These are interrelated, supplementing one another, shaping the individual behaving responsibly vis-à-vis the environment. Therefore, the various topics of environmental protection should in no way be separated and they should be communicated separately to the public.

This is how the situation we observe nowadays develops: people think there is an order of priority among the various topics. Unfortunately, the organisations of the various environmental protection areas, using different systems of concepts, bombard the public with different messages on what to do in order to behave responsibly for the environment.

Holistic thinking is unfortunately not characteristic of the environment protection trade, in spite of the fact that this would result in the better management of the respective topics of the operators, and that a systematic approach would have a far greater effect on consumers. In their own lives, they are able to easily and relevantly incorporate the means of protecting the environment and preventing damage. Adults conveniently push the responsibility on their children by quoting "the next generation will solve it". This is the attitude that calls for change. There is, however, no efficient platform available to them as the kindergarten or school for children, where such environmentconscious activities are incorporated into their everyday lives as fundamental schemes. Adults, on the other hand, if involved as part of internal communication activity in a green office programme and are "obligated" following internal information to exercise daily attention to it, they demonstrate assertive resistance, cooperation (even feigned cooperation) being out of the question. Employees who live a priori environment-consciously, such initiatives work perfectly, and they are the ones who quite probably switched off their computers when they left the office for more than half an hour even before the corresponding notification was issued. Looking at the communication of for-profit companies, they 
are likewise segmented, embracing specific topics only. They have appropriations and objectives, and they will make the specific environmental protection matter connected to their area serve these objectives.

In their communication, they will segment the target group, those concerned and the corresponding messages and set of instruments as per their own interests. To set up a strategy in which everyone is in the target group is impossible on the one hand (or is a question of money), and inefficient on the other.

At the same time, the emphasis is not on selecting the target group, but to support the consumers with this holistic environmental thinking, within which it is possible to highlight our topic of preference. It should be the obligation of everyone to back this up with a system, one that would help understanding as well as better reception of the matter. If substantive CSR (corporate social responsibility) were going on in Hungary today, all profit-oriented enterprises targeting a larger public would incorporate efforts related to sustainable development and environmental projects in their strategies. Of course, nothing is easy when one is to go it alone, hence the non-profit and civic organisations who already have experience in this holistic environmental way of thinking await companies with open arms to join their efforts in this direction. Governmental policies are not helping the situation at present.

With the help of the concepts and their functions introduced by Luhmann, we can model a communication system that can clarify how individual social subsystems (economy, law, science, politics, art, religion, education) map issues related to ecological problems, and which subsystem can take action and at what depth. The author, relying on his own system theory, identifies the challenge in relation to this subject mainly in the question of how the social subsystems can offer solutions to ecological problems.

Table 1. Subsystems of Luhmann (own compilation)

\begin{tabular}{|l|l|l|l|}
\hline SUBSYSTEM & FUNCTION & MEDIUM & CODE \\
\hline Economy & Reducing scarcity & Money & Payment/non-payment \\
\hline Law & $\begin{array}{l}\text { Ensuring the fulfillment of } \\
\text { expectations }\end{array}$ & $\begin{array}{l}\text { Law, } \\
\text { jurisdiction }\end{array}$ & Legal/illegal \\
\hline Science & Producing new knowledge & Truth & True/false \\
\hline Politics & $\begin{array}{l}\text { Producing collectively binding } \\
\text { decisions }\end{array}$ & Power & $\begin{array}{l}\text { Power/powerlessness } \\
\text { government/opposition }\end{array}$ \\
\hline Art & Representing the world & forming, & $\begin{array}{l}\text { convincing/unconvincing } \\
\text { beautiful/ugly }\end{array}$ \\
\hline Education & Selecting for the career & Career & Praise/reproof \\
\hline Religion & Eliminating contingency & Belief & Immanent/transcendent \\
\hline
\end{tabular}

Currently, the tool-sets of social systems have no direct effects on solving ecological problems, they only have social dimensions. Among the subsystems, according to Luhmann, politics has the biggest effect and highest influencing potential in relation to the other subsystems. Politics cannot put anything into effect directly, yet this scene is still the best choice of forum for ecological communication since politics has the largest influence on all the other social subsystems. Our current research verified this. Through centralized planning, hand-held direction, and dominantly one-way communication, the government owns control and removes such collaborations that were already present in the Hungarian market. Though Luhmann has clearly stated that his work (and its system theory background) is not suitable for solving ecological problems, in my opinion, he still took a significant step forward by successfully specifying through his model the social subsystems that are able to become its driving force. (Luhmann, 2010) I agree with him that the political scenery has such huge influence on other subsystems that using leverage or even perhaps pressure, it can promote the state of affairs. 


\section{References}

EUROPEAN ENVIRONMENT AGENCY (2015). The European Environment Bulletin and Outlook. Summary Report. https://www.kowi.de/Portaldata/2/Resources/horizon2020/coop/SOERSynthesis-2015-EN.pdf.

KELLY, George A. (1969). A Mathematical Approach to Psychology. In Clinical Psychology and Personality (1961). The Selected Papers of George Kelly. Wiley. New York.

KOVÁCS Zs. (2019). Sustainability Approach Development Strategy Prepared by the Ministry of Innovation and Technology on behalf of Széchenyi István University Manuscript. Győr. Széchenyi István University.

KÖVECSESNÉ, dr. Gősi Viktória (2015). Környezeti nevelés gyakorlata az erdei iskolában Hazánk Kiadó. Győr.

LUHMANN, Niklas (2006). Bevezetés a rendszerelméletbe. Gondolat.

LUHMANN, Niklas (2010). Ökológiai kommunikáció: képes-e felkészülni a modern társadalom az ökológiai veszélyekre? Budapest. Gondolat.

MIKÓ, Attiláné (2017/1). A Storyline módszer. Módszertani Közlemények.

Municipal waste recycling rates in 32 European countries (2013). https://www.eea.europa.eu/data-andmaps/figures/municipal-waste-recycling-rates-in/municipal-waste-recycling-rates-in. 